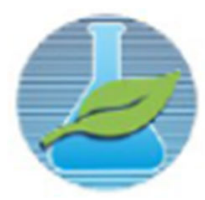

Vol. 02 N. 04 (2016) 031-033
$\mathrm{JCEC} / \mathrm{REQ}^{2}$

Journal

ISSN: 2446-9416

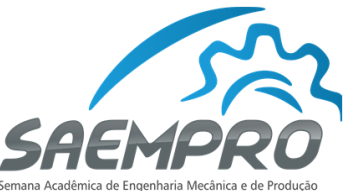

\author{
"EU, A INDÚSTRIA E O MUNDO" \\ 08 a 11 de novembro de 2016 no campus Viçosa da UFV \\ Departamento de Engenharia de Produção e Mecânica - DEP \\ Universidade Federal de Viçosa - UFV
}

\title{
INFLUÊNCIA DA ENERGIA DE SOLDAGEM NA MICROESTRUTURA DE UM AÇO INOXIDÁVEL LEAN DUPLEX
}

\author{
Samuel Francis Magalhães Soares, Douglas Marcelino da Silva, Reginaldo Pinto Barbosa \\ Cento Universitário do Leste de Minas Gerais (UNILESTE-MG), Escola Politécnica \\ Av. Tancredo Neves, 3500, B. Universitário - 35170-056 - Coronel Fabriciano - MG \\ samuel.francis63@gmail.com,douglasmarcelino92@gmail.com, reginaldo.barbosa@aperam.com
}

\section{INTRODUÇÃ̃O}

O Aço Inoxidável Duplex é uma liga capaz de aliar boas propriedades mecânicas e resistência à corrosão, além de boa soldabilidade. É constituído por uma microestrutura bifásica de Ferrita e Austenita em proporções volumétricas próximas de 50\%. Devido a essa combinação, é considerado um material de alto desempenho. Suas principais características ampliam o seu campo de aplicação, a exemplo na indústria química e petroquímica, de papel e celulose, energia nuclear, petróleo e gás, entre outros (Nunes et al., 2009; Souza et al., 2012).

Sua larga utilização em diversos setores industriais necessita constantemente que este material seja submetido a algum processo de soldagem. Entretanto, a soldagem requer alguns cuidados, pois os ciclos térmicos envolvidos no processo, como aquecimento e resfriamento localizados, expansão e contração, podem acarretar alterações nas suas características (Guimarães et al., 2014; Fedele et al., 1999). Ressalta-se ainda que para o aço Lean Duplex SAF 2304, foco deste trabalho, é recomendada a faixa de energia de soldagem de 0,5 a $2,0 \mathrm{~kJ} / \mathrm{mm}$ (IMOA, 2012).

É importante verificar as alterações microestruturais decorrentes da soldagem com intuito de manter o balanço de fases em equilíbrio, bem como a obtenção de Ferrita em teores adequados no metal de solda, sendo que a variação de energia pode influenciar no percentual desta fase.

\section{OBJETIVOS}

Este trabalho tem como objetivo avaliar a influência da energia de soldagem na microestrutura do aço inoxidável Lean Duplex UNS S32304 (SAF 2304) soldado pelo processo com eletrodo revestido, utilizando o consumível AWS E2209-17, a fim de identificar as possíveis alterações microestruturais causadas pela variação do aporte térmico durante o processo.

\section{METODOLOGIA}

Foi realizada a deposição de um cordão de solda pelo processo a arco elétrico manual com eletrodo revestido (SMAW) em chapas de aço do tipo UNS S32304 (SAF 2304), utilizando o consumível E2209-17 e dois níveis de energia distintos. As composições químicas do aço em questão e do metal de adição são apresentadas, respectivamente, nas Tab. 1 e Tab. 2:

Tabela 1 - Composição química do metal base, $\%$ em peso.

\begin{tabular}{cccccccccc}
\hline $\mathrm{C}$ & $\mathrm{Mn}$ & $\mathrm{Si}$ & $\mathrm{Cr}$ & $\mathrm{Ni}$ & $\mathrm{P}$ & $\mathrm{S}$ & $\mathrm{Mo}$ & $\mathrm{N}$ & $\mathrm{O}$ \\
\hline 0,0158 & 1,4834 & 0,4207 & 22,1558 & 4,0183 & 0,0238 & 0,0001 & 0,1982 & 0,1204 & 0,0023 \\
\hline
\end{tabular}

Tabela 2 - Composição química do metal de adição, \% em massa (Weld-Inox, 2015).

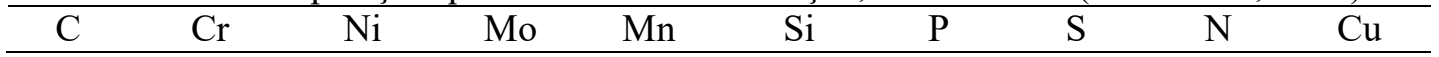




\begin{tabular}{llllllllll}
0,29 & 22,355 & 9,438 & 2,780 & 0,831 & 0,560 & 0,025 & 0,025 & 0,080 & 0,516 \\
\hline
\end{tabular}

Na Tabela 3 são apresentados os parâmetros adotados:

Tabela 3 - Parâmetros de soldagem adotados (Dados da pesquisa, 2016).

\begin{tabular}{ccccc}
\hline $\begin{array}{c}\text { Corpos de } \\
\text { Prova }\end{array}$ & $\begin{array}{c}\text { Energia } \\
(\mathrm{kJ} / \mathrm{mm})\end{array}$ & $\begin{array}{c}\text { Corrente } \\
(\mathrm{A})\end{array}$ & $\begin{array}{c}\text { Tensão } \\
(\mathrm{V})\end{array}$ & $\begin{array}{c}\text { Velocidade de soldagem } \\
(\mathrm{mm} / \mathrm{s})\end{array}$ \\
\hline Nível 1 (CPI) & 0,652 & 72 & 24 & 2,12 \\
\hline Nível 2 (CPII) & 0,977 & 96 & 28 & 2,20 \\
\hline
\end{tabular}

Destas chapas foram retiradas amostras para realização da análise metalográfica por microscopia ótica, cujas etapas de preparação incluíram corte, lixamento, polimento manual implementado com Pasta Diamante e antioxidante DP Azul e ataque químico com reagente Behara.

\section{RESULTADOS}

O balanço de fases de ambos os corpos de prova se comportou dentro do intervalo de 30 a $70 \%$ de Ferrita na zona afetada pelo calor (ZAC) proposto por Messer et al. (2007). A Tabela 4 traz o balanço de fases:

Tabela 4 - Balanço de fases das amostras (Dados da pesquisa, 2016).

\begin{tabular}{cccc|cccc}
\hline & & \% Ferrita & \% Austenita & & & \% Ferrita & \% Austenita \\
\hline \multirow{3}{*}{ CPI } & MB & 49,378 & 50,622 & & MB & 48,630 & 51,370 \\
& ZAC & 71,046 & 28,954 & CPII & ZAC & 68,501 & 31,499 \\
& ZF & 41,322 & 58,678 & & ZF & 41,465 & 58,536 \\
\hline
\end{tabular}

A zona fundida (ZF) das amostras apresentou um comportamento semelhante mesmo em condições de soldagem diferentes. Já a ZAC apontou uma variação relativa na composição de Ferrita. É possível perceber também o equilíbrio bifásico no metal base (MB) do aço Duplex. As micrografias mostram que na ZAC próxima à linha de fusão ocorreram transformações em relação a sua microestrutura original, conforme mostra a Fig. 1:

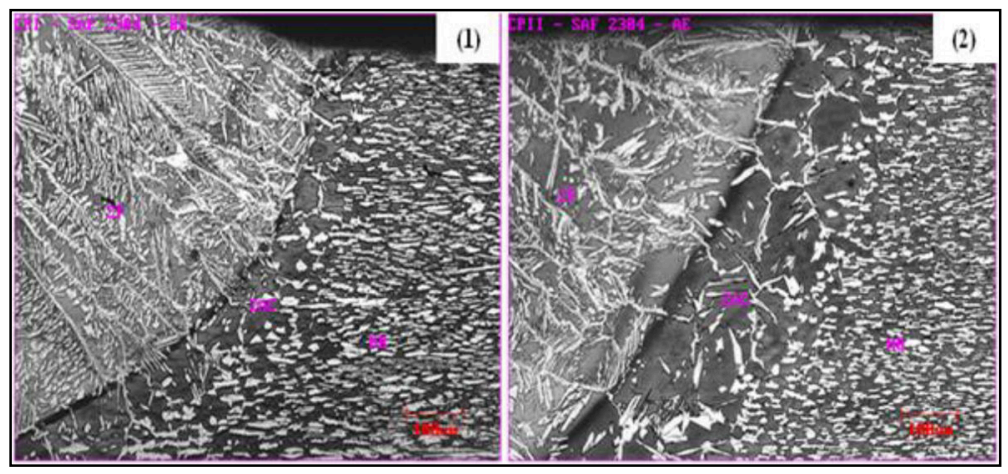

Figura 1- Microestrutura da ZAC próxima a linha de fusão do CPI (1) e CPII (2) (Dados da pesquisa, 2016).

Houve crescimento dos grãos ferríticos (fase escura) próximo à zona de fusão, o que pode levar a uma perda de tenacidade (Nunes et al., 2009). O menor aporte térmico utilizado na soldagem do CPI possibilitou uma menor ZAC com menor extensão da região de granulação grosseira. O tamanho dos grãos austeníticos (fase clara) na ZAC grosseira da amostra do CPII é relativamente superior devido ao maior aporte térmico utilizado, certificando de que existe influência da energia de soldagem na microestrutura. Foram identificadas três morfologias da Austenita em ambos as amostras, sendo elas a alotriomórfica, que se forma em altas temperaturas e cresce nos contornos dos grãos ferríticos no resfriamento, a intragranular, que se formam dispersas em temperaturas baixas (Nunes et al., 2009) e a Widmanstätten, que se apresenta como um emaranhado de agulhas e se forma a partir de taxas de 
resfriamento mais altas (Macêdo, 2012). Contudo, não foi observada a precipitação de fases intermetálicas.

$\mathrm{Na}$ ZAC mais distante da linha de fusão não ocorrem transformações significativas na microestrutura em relação à morfologia da Austenita e ao tamanho de grão. Nas duas condições foram observadas maiores quantidades de Austenita na zona fundida e não foi verificada a falta de fusão.

\section{CONCLUSÕES}

Houve influência da energia de soldagem na microestrutura da ZAC das duas amostras, de maneira que a condição imposta no CPII obteve uma ZAC de granulação grosseira mais extensa. Apesar da diferença de aproximadamente $300 \mathrm{~J} / \mathrm{mm}$ entre os aportes térmicos empregados, o aumento da energia de soldagem não proporcionou um crescimento considerável dos grãos da ZAC mais grosseira.

Foi constatado que com o aumento da energia de soldagem há uma tendência de redução na fração volumétrica de Ferrita. Porém, a variação da energia de soldagem utilizada neste trabalho exerceu pouca influência no balanço de fases da zona fundida.

$\mathrm{O}$ balanço de fases da ZAC e da ZF das amostras soldadas se manteve no intervalo sugerido, o que implica que a faixa de energia de soldagem proposta pela literatura de 0,5 a $2,5 \mathrm{~kJ} / \mathrm{mm}$ deve ser respeitada.

\section{AGRADECIMENTOS}

Os autores do trabalho expressam seus agradecimentos à APERAM SOUTH AMÉRICA, pela cessão das amostras do aço Duplex, à WELD-INOX por fornecer os eletrodos revestidos e ao soldador Élison por contribuir com sua experiência profissional.

\section{REFERÊNCIAS}

FEDELE, R. et al. "Soldagem Multipasse do Aço Inoxidável Duplex UNS S31803 por Eletrodo Revestido". Soldagem \& Inspeção. São Paulo, n. 1, a. 6, 1999.

GUIMARÃES, B.H.D. et al. "Efeito da Energia de Soldagem e da Espessura do Aço Inoxidável Duplex Sobre as Transformações na Zona Afetada Pelo Calor". Revista Brasileira de Aplicações de Vácuo. [S.I], v. 33, n. 1-2, p.1-6, 21 out. 2014.

INTERNATIONAL MOLYBDENUM ASSOCIATION. "Orientações Práticas Para Processamento dos Aços Inoxidáveis Duplex". 2. ed. Londres. 2009. Atualização: 2012.

MACÊDO, H.R.A. "Tratamento Térmico do Titânio e Suas Consequências Sobre as Propriedades Físico-Químicas e de Biocompatibilidade". 2012. 108 f. Tese (Doutorado) - Centro de Ciências Exatas e da Terra, Universidade Federal do Rio Grande do Norte, Natal, 2012.

MESSER, B. et al. "Duplex Stainless Steel Welding: Best Practices". Stainless Steel World. [s.1.], p. 42-49, 2007.

NUNES, E.B. et al. "Efeito Dos Parâmetros de Soldagem na Microestrutura do Aço Inoxidável Duplex UNS S31803 Pelo Processo Eletrodo Revestido". In: Congresso Brasileiro e P\&D em Petróleo e Gás, 5. 2009, Fortaleza. Anais Eletrônicos... Fortaleza: UFC, 2009.

SOUZA, C. S. "Avaliação da Resistência à Corrosão Localizada do Aço Inoxidável Lean Duplex UNS S32304 Soldado Pelos Processos SMAW, GMAW e FCAW'. 2012. 100 f. Dissertação (Mestrado) - Curso de Engenharia Química, Universidade Federal de Minas Gerais, Belo Horizonte, 2012.

WELD-INOX Soldas Especiais. "Certificado de Qualidade: NBR ISSO 9001-2008". Diadema: WeldInox, 9 de março de 2015. Sistema de gestão de Certificado. 